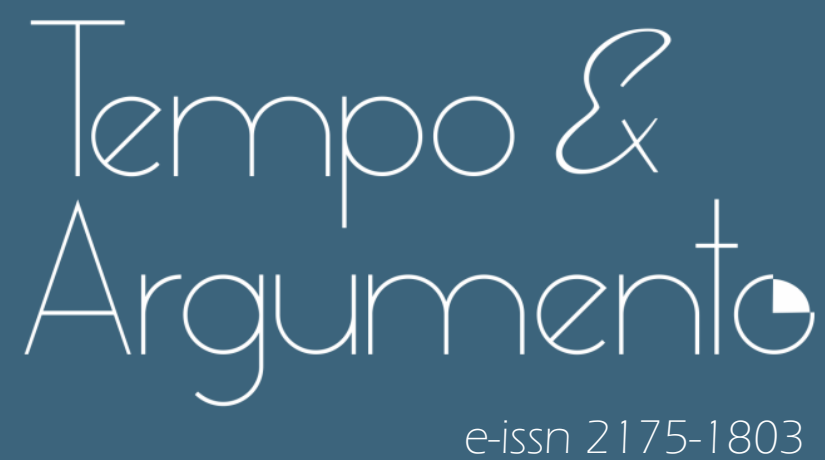

\title{
Senghor, o intelectual que precisa ser apresentado ao grande público brasileiro
}

Resenha da obra:

DURÃO, Gustavo de Andrade. Léopold Sédar Senghor: uma narrativa sobre

o movimento da Négritude. Curitiba: Appris, 2020, 167 p.

- Mírian Cristina de Moura Garrido

Doutora em História e Sociedade pela Universidade Estadual Paulista "Júlio

Mesquita Filho" (UNESP). Atualmente realiza Estágio Pós-Doutoral na Universidade

Federal de São Paulo (UNIFESP).

São Paulo, SP - BRASIL

lattes.cnpq.br/9958895252410582

miriangarrido@hotmail.com

(i) orcid.org/0000-0002-0995-0489

Para citar esta resenha:

DURÃO, Gustavo de Andrade. Léopold Sédar Senghor: uma narrativa sobre o movimento da négritude. Curitiba: Appris, 2020, 167 p. Resenha de: GARRIDO,

Mírian Cristina de Moura. Senghor, o intelectual que precisa ser apresentado ao grande público brasileiro. Revista Tempo e Argumento, Florianópolis, v. 12, n. 30, e060 1. maio/ago. 2020.

doi http://dx.doi.org/10.5965/2175180312302020e0601 
Gustavo de Andrade Durão

\section{LÉOPOLD SÉDAR SEOHOR}

Uma narrativa sobre o Movimento da Négritude

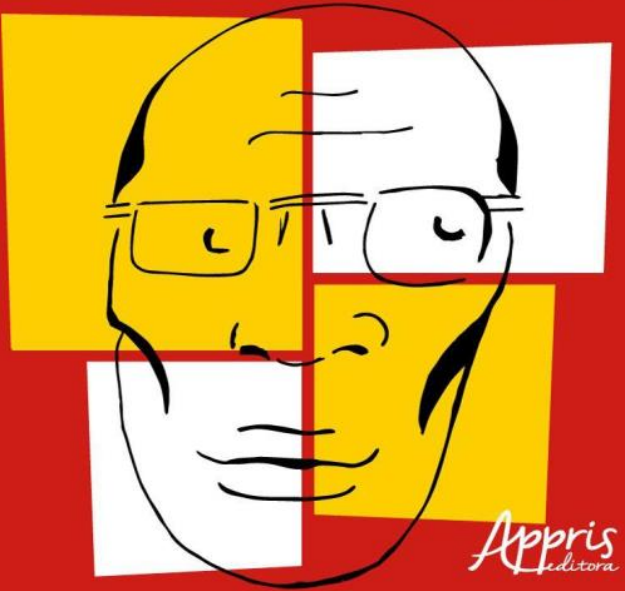

Resenha da obra:

DURÃO, Gustavo de Andrade. Léopold Sédar Senghor: uma narrativa sobre o movimento da Négritude. Curitiba: Appris, 2020, 167 p.

Graduado em História pela Universidade Católica do Rio de Janeiro, mestre pela Universidade Estadual de Campinas, doutor em História Comparada pela Universidade Federal do Rio de Janeiro, pós-doutor em dois estágios, um pela PUC-Rio, outro pela UFRRJ, atual professor da Universidade Estadual do Piauí, Gustavo de Andrade

Durão emerge nos circuitos acadêmicos como um jovem historiador africanista, que merece atenção pela qualidade das pesquisas e pelos temas explorados.

No livro aqui resenhado, ao selecionar Léopold Sédar Senghor como sujeito investigado, Durão abre caminhos para uma literatura até agora pouco explorada no Brasil, uma vez que há uma lacuna na publicação das obras do intelectual. A pesquisa e sua publicação são sintomas de novos momentos para a historiografia sobre a África no país, reflexo da Lei 10.639, de 2003, que exigiu a introdução da disciplina História da África nas escolas brasileiras de ensino básico, pressionando as universidades a introduzir a matéria nos currículos universitários, favorecendo o adensamento das pesquisas sobre a África e o conhecimento a respeito dos intelectuais daquele continente.

Análises sobre Senghor já faziam parte das preocupações do pesquisador durante o mestrado, período de gérmen do livro que veio a público nove anos depois da defesa. A leitura da obra, contudo, informa que a pesquisa foi revisada e ampliada. Sua escrita didática e a construção de contextos em que se desdobra a temática abordada favorecem, também, o uso do livro como referência aos graduandos. 
O livro está dividido em três capítulos, com as balizas cronológicas definidas dos anos 1920 a 1945. "A redescoberta da África”, “A 'Négritude’ cultural revisitada" e "A 'Négritude' e suas transformações”. Esses capítulos constroem um itinerário que permite a compreensão dos intelectuais e contextos que influenciaram a formação do movimento da 'Négritude'. O entendimento do que seja 'Négritude' desempenhou papel central na conceituação das produções do sujeito aqui investigado. Semelhante função desempenharam os desdobramentos deste movimento a partir dos periódicos que o construíram de forma mais concreta, como afirma o próprio Gustavo Durão, até o fim da Segunda Guerra Mundial, quando as bases de sustentação do assimilacionismo francês em África foram desestruturadas.

O livro permite compreendermos que as primeiras décadas do século XX marcam o imperialismo em África, mas, ao mesmo tempo, despertam curiosidade sobre a arte e a cultura africanas. O retorno ao "primitivo", ao original, é impulsionado no meio artístico por europeus (como Picasso e Matisse). Contudo, se a "arte negra" era lida por uma estética grotesca, o que, por vezes, reforçava as concepções do darwinismo social, para os negros (africanos ou não) ela poderia ser reinterpretada por outra via. Ela constituiu o meio de abertura para a construção de uma cultura outra, aprofundada pelas expressões artísticas que emergiam nas primeiras décadas do século XX, como o jazz e as manifestações artísticas do Harlem Renaissance. Segundo o autor, após a Grande Guerra:

[...] esse tumulto negro havia chegado a Paris e os cabarés de Montmartre eram os ambientes mais propícios para que a intelectualidade desse período se reunisse apreciando o valor da música e da dança dos negro-americanos. O primitivo e o exótico estavam em alta, apesar das críticas; o Jazz ia se proliferando como algo verdadeiramente belo, novo e bom de ouvir. Era chegada a "supremacia dos negros"; a França estava aceitando isso, fosse como forma de contestação ao crescimento da industrialização, fosse para fugir ao "trauma da guerra". O Jazz e as formas da "arte negra" alcançaram grande penetração no espaço cultural europeu, fazendo parte de um grande movimento (DURÃO, 2020, p. 33 - grifos meus).

Essa "batalha" era travada no campo da cultura, mas vinha sendo disputada também nos espaços intelectuais e políticos. Como bem observam os 
historiadores W.E.B. Du Bois e Marcus Garvey, o "primitivo" e o "exótico" atuaram para a propagação das ideias de comunidade negra comum, a que levava em consideração a África e a Diáspora como ligação de africanos e afrodescendentes, e ainda atuaram na construção de possibilidades de reversão dessa situação, mesmo que com estratégias distintas.

É este o contexto do surgimento do movimento da 'Négritude', analisado por Durão através de um de seus construtores e expoentes:

Enquanto Hughes, Cullen e MacKay [Harlem Renaissance] estavam produzindo suas obras e poesias, ou quando DuBois estava organizando os congressos e as associações dos negros, a intelectualidade das colônias francesas da África, do Caribe e das Antilhas estavam tendo a oportunidade de estudar nas metrópoles e tendo acesso às suas obras. Senghor deixa claro que a geração dos "Novos Negros" foi de fundamental importância na produção artística e para a valorização do negro como ser humano, com orgulho de todas as suas potencialidades intelectuais (DURÃO, 2020, p. 49).

Expressão dessa valorização é a própria ressignificação do termo atribuído à manifestação cultural, literária e ideológica, assim como o prefixo négre, originado do termo "negro", até então pejorativo, adicionado ao tude, que exprime a ideia de "grupo". É curioso como, em diferentes partes do mundo, exista essa iniciativa de usar termos pejorativos e ressignificá-los. É o caso do movimento negro contemporâneo, ao qual tenho dedicado minhas pesquisas. O movimento atribui a si mesmo o termo negro, assim como aos militantes mais atuais, que reclamam para si a identificação enquanto pretos. Elementos como esse não são coincidências; na prática, reforçam um elemento central dos estudos africanos e diaspóricos a respeito da transnacionalidade da luta por identificação positiva e antirracista.

A obra é importante ao indicar, ainda, que, no processo de construção dos discursos do movimento 'Négritude', a valorização da África não é vista somente pela busca do passado histórico. Era necessário redescobrir os valores, a expressão, a beleza e a dignidade humana para se alcançar a inserção do negro na sociedade e lutar contra o racismo. É neste cenário que o autor afirma que a ‘Négritude'é vista, pelo próprio Senghor, como "patrimônio cultural” de todos os 
africanos e descendentes, uma resposta aos valores culturais franceses e às práticas sistemáticas de colonização do corpo e da mente.

Dentro da construção dessas posições, aos leitores é valido observar também o cenário dos impressos produzidos e que circulam nesse ambiente francês, que, por vezes, o extrapolam. A diversidade da nacionalidade dos sujeitos envolvidos nas revistas, como a Revue du Munde Noir, que teve edições em francês e inglês, indicam a efervescência de pessoas e ideias, da mesma forma que a rede de comunicação e informação de expressões que emergiam no seio desses sujeitos ou em outros espaços, por eles informados ao público. É, inclusive, ao Légitime Défense que Senghor atribui a origem da tríade Senghor (senegalês), Césaire (martinicano) e Damas (franco-guianense), reforçada pela participação no L'Étudiant Noir, expressão da união de elementos que se querem universais entre os afrodescendentes.

Destaque, ainda, para o leitor, para a construção do cenário dos anos 1930 e 1940, marcados por uma gama variada de intelectuais e artistas que, gradativamente, inserem a África no debate, distanciando-se da defesa do assimilacionismo e do colonialismo, propondo uma perspectiva de África e afrodescendentes pensada pelos próprios agentes. $O$ dado reforça a construção do autor do livro sobre a existência de uma rede de diálogo intelectual, como por ele cunhado, e sobre um projeto para a população negra sob qualquer tipo de exclusão.

Se pairou, durante certo tempo, um demérito sobre o pensamento e a obra de Senghor, fruto do paradoxo da valorização do continente africano, concomitante ao desejo de "ser francês" (presente em parte de sua trajetória), somada às negociações de independência do Senegal lideradas por Senghor, o intelectual é aqui observado de forma mais profunda e complexa. Explico, e para tal retorno ao título da obra: o maior mérito do livro é apresentar ao leitor brasileiro "uma narrativa", deixando, assim, estabelecido a priori a necessidade de ampliarmos as narrativas a respeito dos sujeitos não hegemônicos, de compreendermos as trajetórias de indivíduos como fenômenos não lineares, compostos por inúmeras influências, e a emergência de compreendermos que há múltiplos relatos sobre os eventos. 
Por fim, o livro e o autor nos ajudam a compreender que a História da África não pode ser desassociada da perspectiva transnacional das discussões sobre raça; em especial, não pode ser compreendida na ausência de intelectuais africanos, com destaque para aqueles que deram base ao movimento da 'Négritude', em especial Senghor. O livro parece ter a intenção de popularizar seu pensamento no Brasil, dada a ausência de traduções de suas obras no país. O desejo final é que o esforço do pesquisador seja bem-sucedido e auxilie na emersão de outras novas narrativas.

Universidade do Estado de Santa Catarina - UDESC

Programa de Pós-Graduação em História - PPGH

Revista Tempo e Argumento

Volume 12 - Número 30 - Ano 2020

tempoeargumento@gmail.com 